ШАТИЛОВ Александр Борисович - кандидат политических наук, доцент; декан факультета социологии и политологии, профессор департамента политологии факультете социальных и и массовых коммуникаций Финансового университета при Правительстве РФ (125993, Россия, г. Москва, ГСП-3, Ленинградский пр-кт, 49; Absh71@yandex.ru)

\title{
НОВЫЙ РЕГИОНАЛЬНЫЙ СЕПАРАТИЗМ В РОССИЙСКОЙ ФЕДЕРАЦИИ (2014-2021 гг.)
}

\begin{abstract}
Аннотация. Несмотря на то что на протяжении почти уже 20 лет в России сохраняется относительная политическая стабильность, тем не менее существуют риски для ее государственности, которые проявляются на латентном уровне. В частности, речь идет о новом региональном сепаратизме, который по объективным и субъективным причинам зреет в целом ряде субъектов федерации. Статья посвящена анализу данного феномена. Автор приводит свою типологию неосепаратизма. При этом отмечается, что последний, в отличие от «брутального» сепаратизма 1990-х гг., является достаточно умеренным и “сдержанным», хотя при определенных условиях может стать катализатором дестабилизации в целом ряде регионов страны.
\end{abstract}

Ключевые слова: сепаратизм, Российская Федерация, регионы, субъекты Федерации, государственность, стабильность, риски

$\mathrm{P}$ егиональный сепаратизм стал одним из наиболее серьезных вызовов Российской Федерации в «лихие девяностые». Слабость центральной власти, дефицит ресурсного потенциала, развал силовых структур привели к очень опасной ситуации, когда суверенитета и самоопределения требовали не только национальные республики, но даже «русские» регионы (Свердловская область, Калининград, Сибирь и др.). Ценой колоссальных усилий, а также первоначальных уступок («берите суверенитета столько, сколько сможете проглотить») Кремлю удалось затормозить процесс распада страны и дотянуть до конца 1990-х гг., когда сложились благоприятные предпосылки для «реинтеграции» ее территории. Появление популярного сильного лидера (В.В. Путин), помноженное на позитивную экономическую конъюнктуру (резкий рост цен на углеводороды) привело к тому, что федералам удалось перейти в контратаку и подавить сопротивление региональных элит. Введение федеральных округов и полпредов, ревизия регионального законодательства и приведение его в соответствие с федеральным, реформа Совета Федерации и еще целый пакет иных антикризисных мер позволили восстановить вертикаль власти и снять проблему сепаратизма в субъектах РФ. Одновременно была проведена показательная жесткая зачистка мятежной Ичкерии, которая надолго отбила желание у национальных республик требовать независимости и выхода из состава России. После этого сепаратизм резко пошел на спад, региональные элиты были поставлены перед выбором либо признать централизм, либо бесславно завершить свою карьеру, зачастую с уголовным делом в придачу, население провинции было вовлечено в федеральную политическую, идеологическую, экономическую и социальную повестку. Так продолжалось примерно до 2013-2014 гг., когда созрели предпосылки для нового витка регионального сепаратизма. Правда, на сей раз он носил не открытый, а латентный характер. Причины тому были как объективные, так и субъективные.

К объективным можно отнести:

- вынужденную переориентацию федерального центра на внешнеполитический контур; 
- диспропорции в социально-экономическом развитии страны в пользу столиц и мегаполисов;

- снижение вовлеченности большинства регионов в федеральную повестку дня;

- подрывные действия зарубежных спецслужб, а также институтов «мягкой силы».

Что же касается субъективных причин, то они видятся таким образом:

- подспудная, но весьма активная игра региональных элит против федерального центра;

- формирование у населения провинции ощущения «брошенности» и обиды на Кремль за недостаточное внимание к местным проблемам;

- постепенное распространение западных либеральных идей «многосоставности» и «Полиидентичности»;

- создание и культивирование новых региональных квазисепаратистских мифов и образов.

В итоге, анализируя новый региональный сепаратизм в Российской Федерации периода 2014-2021 гг., можно выделить следующие типы: сепаратизм административно-политический, культурно-исторический и этнокультурный, этнорелигиозный, криминальный, автаркический.

Сепаратизм административно-политический связан с латентной игрой многих региональных элит против федерального центра. При этом такая игра ведется где-то с целью возврата себе ресурсов и полномочий, где-то с целью свалить ответственность за ухудшение жизни на региональном уровне на Москву. Особое распространение он получил после 2014 г. в условиях социально-экономического кризиса и «войны санкций» 1 . Стремясь избежать ответственности перед местным населением, региональное руководство через подконтрольные СМИ стремилось (и стремится) переложить вину за проблемы на центр, а достижения федерального происхождения (например, введение в школах бесплатных обедов ${ }^{2}$ ) приписать своему мудрому и эффективному управлению. И хотя федеральный центр пытается активно противодействовать такой двуличной политике регионалов (путем регулярной ротации кадров, назначения на губернаторские позиции федеральных чиновников и пр.), в целом ситуация существенно не меняется.

Сепаратизм этнокультурный и культурно-исторический наблюдается в тех субъектах РФ, которые в исторической ретроспективе так или иначе противопоставляли себя Москве или шире - Российскому государству. Причем он касается как национальных республик, так и собственно «русских» регионов. В частности, в республиках местные элиты для консолидации вокруг себя населения нередко обращаются к спорным, а иногда «подрывным» темам и мифам (вроде «русского разорения Казани» ${ }^{3}$ или «имперского геноцида народов в ходе кавказских войн» ${ }^{4}$ ). Такого рода акцентировки откровенно бьют по межнациональной стабильности в РФ, подпитывают национальные обиды и претензии, мешают выработке общероссийской идентичности.

1 https://www.rbc.ru/newspaper/2016/02/18/56c43ec19a794753eb821f7f (проверено 30.06.2021).

2 https://news.rambler.ru/politics/44683353-furgala-ulichili-v-ispolzovanii-besplatnyhshkolnyh-obedov-v-kachestve-piara/ (проверено 30.06.2021).

3 https://eadaily.com/ru/news/2021/06/03/dlya-chego-v-tatarstane-uchredili-den-pamyati -shahidov-mnenie? utm_source=yxnews\&utm_medium =desktop\&utm referrer $=$ https $\% 3 \mathrm{~A} \% 2 \mathrm{~F} \% 2 \mathrm{Fyandex.ru} \% 2 \mathrm{Fnews} \% 2 \mathrm{Fsearch} \% 3 \overline{\mathrm{Ftext}} \% 3 \mathrm{D}$ (проверено 25.06.2021)

4 https://www.kavkazr.com/a/31266983.html?utm_source=yxnews\&utm_medium=desktop\& utm_referrer $=$ https $\% 3 \mathrm{~A} \% 2 \mathrm{~F} \% 2 \mathrm{Fyandex.ru} \% 2 \mathrm{Fnews} \% 2 \mathrm{Fsearch} \% 3 \mathrm{Ftext} \% 3 \mathrm{D}$ (проверено $25.0 \overline{6} .2021)$. 
Интересно, что идеи «самобытности» и региональной «особости» культивируются и в ряде «русских» областей. Так, например, в Калининградской обл. в местном истеблишменте сложилась и активно заявляет о себе «партия Кенигсберга»; в Твери до сих пор существует культ князя Михаила Тверского, «умученного от москвитян»; в целом ряде сибирских регионов имеют место неообластнические настроения под бело-зеленым флагом [Зайнутдинов 2012].

Еще более проблемной является ситуация в Республике Крым, где форсированная реинтеграция привела к тому, что серьезных кадровых чисток среди местной элиты не произошло, и многие управленческие позиции (в т.ч. ключевые) до сих пор занимают проукраинские и русофобские элементы ${ }^{1}$.

Подспудным сепаратизмом характеризуется также деятельность целого ряда казачьих организаций и структур в ряде субъектов РФ (особенно на Кубани и в Ростовской обл.). Это выражается в целом ряде моментов:

- в жестком противопоставлении казаков «иногородним»;

- требованиях признания особой казачьей национальности;

- требованиях широкого казачьего самоуправления;

- демонстративном культивировании специфических сторон казачьего быта и особого «казачьего языка» 2 ;

- продвижении идей «Казакии» - сепаратистского проекта ряда казачьих лидеров времен Гражданской войны и эмиграции;

- попытках реабилитации казаков-коллаборационистов, во время Великой Отечественной войны примкнувших к гитлеровцам (атаман П.Н. Краснов, Г. фон Паннвиц, А.Г. Шкуро), а также в стремлении придать коллаборационистам образ мучеников (трагедия в Лиенце) ${ }^{3}$.

При этом надо отметить тот факт, что федеральные и региональные власти явно недооценивают казачий латентный сепаратизм. Более того, многие представители регионального руководства так или иначе включены в казачьи проекты, в т.ч. идеологически сомнительные. Чего стоит только инициатива Ростовстата (региональный орган Федеральной службы госстатистики), который создал словарь национальностей к переписи населения 2021 г. В нем более двух тысяч возможных вариантов ответов на вопрос о национальной принадлежности. Из них с использованием слова «казак» - тринадцать вариантов. В справочник включены словосочетания «донские казаки», «русские казаки», «православные казаки» 4 .

Этнорелигиозный сепаратизм в настоящий момент связан в основном с прозелитской и миссионерской деятельностью иностранных акторов на территории РФ. При этом если федеральной власти в целом удалось отвадить от российских регионов радикалов (ваххабитов, ИГИЛ 5 и пр.), то ситуация с зарубежными представителями «мягкой силы» гораздо хуже. В частности, в настоящее время российское Поволжье активно осваивается различного рода зарубежными организациями светско-религиозного толка в диапазоне от пантюркистов до гюленовцев. При этом местные власти (например, в Татарстане)

1 http://evrazia.org/news/47718?utm_source=yxnews\&utm_medium=desktop\&utm_referrer $=$ https $\% 3 \mathrm{~A} \% 2 \mathrm{~F} \% 2$ Fyandex.ru\%2Fnews $\%$ 2Fsearch\%3Ftext $\% 3 \overline{\mathrm{D}}$ (проверено 25.06.2021).

2 https://www.youtube.com/watch?v=FOctI6Qd6Ro; https://краеведдона.pф/literatura-okazacestve/o-proishozdenii-donskih-kazakov-i-ih-azyke (проверено 23.07.2021).

3 http://www.rapsinews.ru/incident_publication/20200324/305606963.html?utm_source= yxnews\&utm_medium =desktop\&utm_referrer $=$ https $\% 3 \mathrm{~A} \% 2 \mathrm{~F} \% 2 \mathrm{Fyandex} . \mathrm{ru} \% 2 \mathrm{Fnews} \%$ 2Fsearch\%3Ftext\%3D (проверено 25.06.2021)

4 https://www.politnavigator.news/na-starye-grabli-na-yuge-rossii-sozdayut-predposylki-dlyaseparatizma.html (проверено 23.07.2021).

5 Организация, запрещенная в Российской Федерации. 
[Диков 2016] обычно не только не чинят препятствия таким миссионерам, но даже весьма интенсивно с ними взаимодействуют, поощряя их «благотворительную» и «гуманитарную» деятельность ${ }^{1}$.

Определенный латентный сепаратистский потенциал таит в себе не до конца искорененный региональный криминалитет. В начале нулевых годов федеральная власть в целом сумела справиться с преступностью на местах. Некоторые ОПС и ОПГ были разгромлены («Общак» на Дальнем Востоке, «Слоны» в Рязани, тамбовские в Санкт-Петербурге, ореховские и измайловско-гольяновские в Москве), другие абсорбированы и де-факто легализованы в обмен на гарантии своей декриминализации («Уралмаш» в Свердловской области, солнцевские в Москве, быковцы в Красноярском крае). Тем не менее, как показала практика, зачастую региональная преступность не столько «перевоспиталась», сколько мимикрировала и затаилась в ожидании лучших времен. Однако с 2014 г. наблюдаются попытки консолидации оргпреступности, в т.ч. на региональном уровне. Это было связано, с одной стороны, с переориентацией федеральной власти на решение внешнеполитических проблем, с другой - с социально-экономическим кризисом, который больнее всего ударил по российской провинции. Кроме того, усугубляя ситуацию на местах, оргпреступность активно использует недовольство населения «высокомерием» и «эгоизмом» федералов (москвичей). При этом деятельность регионального криминалитета нередко приобретает политические формы. Так, в 2020 г. федеральная власть была вынуждена запретить функционирование неформального криминального движения АУЕ (расшифровывается как «Арестантское уголовное единство»), которое приобрело значительное распространение среди региональной молодежи ${ }^{2}$.

В ответ в 2020 г. оргпреступность попыталась дать власти политический бой. Воспользовавшись арестом губернатора Хабаровского края С.И. Фургала (в свое время имевшего отношение к ОПС «Общак»), местный криминалитет и аффилированная с ним часть местной элиты сумели спровоцировать массовые беспорядки, которые приобрели не только региональный, но федеральный и даже международный резонанс. В итоге ценой колоссальных усилий Москве с трудом удалось «заморозить» конфликт, но напряженность в ее отношениях с местной элитой осталась.

Активизация регионального криминалитета не осталась без внимания силовиков, которые провели ряд превентивных жестких мероприятий. Так, например, ими была осуществлена «зачистка» красноярского «авторитетного» предпринимателя Анатолия Быкова, который в 2000-2019 гг. вел интенсивную политическую деятельность в Красноярском крае (успешно участвовал в выборах в региональное Законодательное собрание, публично поддерживал избирательные блоки «Евразийский Союз» и «Патриоты России», направлял обращения с изложением «народных чаяний» В.В. Путину и т.д.). Итогом такой явно избыточной активности (особенно с учетом имевшегося на него у правоохранителей серьезного компромата) стало его задержание сотрудниками МВД и ФСБ России 5 мая 2020 г. по обвинению в совершении тяжких преступлений.

Очень своеобразным является автаркический сепаратизм, который связан с отдаленностью отдельных территорий и их внутренней консолидацией на основе местного патриотизма и культа «малой исторической Родины». Отчасти такие тенденции характерны для населения и элит Камчатки, Сахалина,

1 https://eadaily.com/ru/news/2020/11/14/tatarskie-nacionalisty-i-azerbaydzhan-sblizheniena-osnove-pantyurkizma (проверено 25.06.2021).

2 https://lenta.ru/brief/2020/08/17/aue/ (проверено 25.06.2021). 
Дальнего Востока, которые воспринимают себя, с одной стороны, как особый пограничный форпост России, с другой - как особую общность, фактически отрезанную от Большой земли [Маркелова 2016]. Наиболее характерно данный вид латентного сепаратизма проявился в конфликте «Архангельская область vs Ненецкий автономный округ». В нулевых годах Москва неоднократно предпринимала усилия по объединению данных регионов, однако каждый раз натыкалась на единодушное сопротивление «северян» - руководства и населения НАО. Более того, на референдуме 1 июля 2020 г. НАО стал единственным субъектом РФ, который проголосовал против поправок в Конституцию, причем глава округа Юрий Бездудный открыто заявил, что такое протестное волеизъявление последовало в ответ на «интеграционные» инициативы центра ${ }^{1}$.

Подводя итоги обзора, следует сказать, что пока региональный сепаратизм в РФ носит латентный характер и не угрожает ее государственности. Однако такая ситуация будет сохраняться до тех пор, пока руководству страны удастся поддерживать относительную стабильность в политике и социально-экономической сфере. В случае же обострения (по тем или иным причинам) обстановки данный протосепаратизм может стать катализатором центробежных тенденций.

\section{Список литературы}

Диков А.Б. 2016. Региональное президентство и институты сепаратизма в тюркских республиках России: современный этап. - Вестник МГОУ. Сер. История и политические науки. № 4. С. 101-112.

Зайнутдинов А.Э. 2012. Цивилизационная идентичность Сибири: от областничества рубежа XIX-XX веков к современному сибирству. - Журнал социологии и социальной антропологии. Т. 15. № 2. С. 81-97.

Маркелова А.А. 2016. Проблема регионального сепаратизма в современной России (на примере Сибири и Дальнего Востока). - Актуальные проблемы развития человеческого потенциала в современном обществе: материалы III Международной научно-практической интернет-конференции. Пермь: Изд-во ПГНИУ. С. 215-217.

SHATILOV Aleksandr Borisovich, Cand.Sci. (Pol.Sci.), Associate Professor; Dean of the Faculty of Sociology and Political Science, Professor of the Department of Political Science, Faculty of Social Sciences and Mass Communications, Financial University under the Government of the Russian Federation (49 Leningradsky Ave, GSP-3, Moscow, Russia, 125993;Absh71@yandex.ru)

\section{NEW REGIONAL SEPARATISM IN THE RUSSIAN FEDERATION (2014-2021)}

Abstract. Despite the fact that for almost 20 years in Russia there has been relative political stability, nevertheless, there are risks to its statehood, which are manifested at a latent level. In particular, the author is talking about a new regional separatism, which for objective and subjective reasons is ripening in a number of subjects of the Federation. The article is devoted to the analysis of this phenomenon. The author gives his own typology of neoseparatism and notes that the latter, in contrast to the "brutal» separatism of the 1990s, is rather moderate and restrained one. Although under certain conditions, it can become a catalyst for destabilization in a number of regions of the country.

Keywords: separatism, Russian Federation, regions, subjects of the Federation, statehood, stability, risks

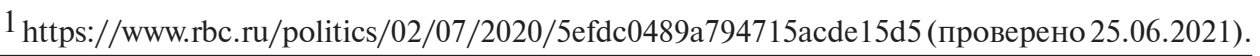

